\title{
ON THE TOXIN FOR LEUKOCYTES PRODUCED BY STREPTOCOCCI (STREPTOLEUKOCIDIN)
}

\author{
YASUSHI NAKAYAMA
}

\author{
From the John McCormick Institute for Infectious Diseases, Chicago
}

Ruediger ${ }^{1}$ found that the filtrates of virulent streptococcus cultures might suspend the destruction of nonvirulent streptococci by leukocytes. A little later, from observations on the appearance of leukocytes during phagocytosis in vitro, Hektoen ${ }^{2}$ made this statement:

So far as our observations have extended centrifugated culture fluids of virulent streptococci, staphylococci and anthrax bacilli reduce phagocytosis of the corresponding nonvirulent strains, principally, I believe, through direct action on the leukocytes, because the fluids in question have but a comparatively slight inhibitive or destructive effect on the opsonin in normal serum, but reduce greatly by one hour's contact the phagocytic power of leukocytes with respect to previously sensitized bacteria. In full harmony with this loss in phagocytic power are the marked functional and morphologic disturbances in the leukocytes placed in fluid containing the products of the growth of virulent bacteria. Thus, when leukocytes are placed in the culture fluids of a virulent streptococcus and examined from time to time on the warm stage, they are seen to lose ameboid movement and to swell greatly in from 30 to 60 minutes, whereas the leukocytes in control experiments remain normal in form and motion several times as long."

M'Leod $^{3}$ noted a leukocidal effect of certain streptococci in rabbits in vivo, but he did not succeed in demonstrating any leukocidal action with streptococcal filtrates.

From these observations it may be concluded that virulent streptococci or their culture fluids may have an unfavorable action on leukocytes, but the subject apparently has not been studied systematically.

\section{BACT-ERIAL LEUKOCIDIN}

Generally speaking, the production by bacteria of substances that are toxic for leukocytes has received little attention with the exception of the leukocidin produced by staphylococci. Van de Velde injected clear filtrates of 24-hour cultures of Staph. aureus in the pleural cavity of rabbits and found that the leukocytes changed, the nuclei becoming distinct and ameboid movement lost. When leukocytes were added to the filtrate in a test tube and left in the incubator for 24 hours, the same result was obtained. He named this toxic sub-

Received for publication Jan. 5, 1920.

1 Jour. Am. Med. Assn., 1905, 44, p. 198.

2 Ibid., 1906, 46, p. 1407.

Jour. Path. \& Bacteriol., 1915, 19, p. 392.

- LaCellule, 1894, 10, p. 403. 
stance leukocidin. Borrissow ${ }^{5}$ placed small capillary tubes filled with bacteriafree culture fluids of Staph. aureus, under the skin of rabbits and dogs, and noted that leukocytes not only were attracted by the fluid, but were also destroyed. When he left the tube subcutaneously in a dog for four days, many broken-down leukocytes were found in the fluid.

According to Deny and Van de Velde, staphylococcus leukocidin is a metabolic product that acts not only on leukocytes, but on other cells, such as connective tissue cells and the cells of the sympathetic nervous system. They were not able to demonstrate the presence of any leukocidin when they injected into the pleural cavity, colon, diphtheria or typhoid bacilli or pneumococci.

Bail $^{\top}$ cultivated virulent Staph. aureus in $40.0 \mathrm{cc}$ of $1 \%$ glycerol with $15 \mathrm{cc}$ of rabbit serum, and in $80 \mathrm{c} \mathrm{c}$ of broth with $20.0 \mathrm{cc}$ of the fluid of ovarian cysts. In either medium the largest quantity of leukocidin was realized in cultures which had stood for 11 days. He injected into the pleural cavity of rabbits of about equal size and weight, from $7.0-12.0 \mathrm{cc}$ of a germ-free aleuronat suspension, and after 24 hours he injected into the same place from 1.0-3.0 $\mathrm{cc}$ of filtrate containing leukocidin. When unheated filtrate was injected, the leukocytes degenerated in the course of from $1-1 \frac{1}{2}$ hours, but later normal leukocytes appeared in large quantity, the leukocidin by this time having disappeared.

Georgiewski ${ }^{8}$ states that the culture fluid of $\mathrm{B}$. pyocyaneus was injurious to leukocytes and that antipyocyaneous serum did not neutralize this effect.

Eisenberg ${ }^{\circ}$ also found that in staphylococcus filtrates leukocytes rapidly become rounded, and the protoplasm homogeneous, losing its granules; the crescent-shaped nuclei were dissolved or fused into one lump.

In the study of leukocidin, the work of Neiser and Wechsberg ${ }^{10}$ is especially notable. They skillfully made use of the reducing power of leukocytes in their study of the production of leukocidin by staphylococci. According to their results, when staphylococci are cultivated in an alkaline medium, leukocidin appears after four days, and after one week the production reaches its maximum. The amount of leukocidin depends on virulence, the strains of greater virulence producing a larger amount. The amount of leukocidin may be increased if the virulence is increased by passage through the animals, in the case of strains that have been grown artificially long enough to lose their virulence. They found that this leukocidin was destroyed by heating at $56 \mathrm{C}$. for a short time, and that the normal serum of horse and man contains antiletkocidin which could be produced also by immunization.

Thus it appears that the leukocidin production by staphylococci has been studied fairly completely by several authors, but the production of leukocidin by streptococci and other bacteria has not been studied so thoroughly.

\section{TECHNIC}

In this work on the leukocidin produced by streptococci, I have used the same medium that $I$ used in the study ${ }^{11}$ of streptolysin,

\footnotetext{
5 Ziegler's Beiträge, 1894,16 , p. 432.

- LaCellule, 1895, 11, p. 395.

T Arch. f. Hyg., 1898, 32, p. 133.

s Ann. de 1'Inst. Pasteur, 1899, 13, p. 298.

- Comp. rend. Soc. de Biol, 1907, 62, p. 491.

${ }^{10}$ Ztschr f. Hyg. u. Infektionskr., 1901, 36, p. 299.

11 Jour. Infect. Dis., 1919, 25, p. 509.
} 
namely, broth (plain or $0.2 \%$ glucose) containing serum in a $1: 9$ dilution. The filtrates (Maasen) of cultures of streptococci in this medium may contain substances that act as toxins for leukocytes, and in this article active filtrates are designated simply as leukocidin or streptoleukocidin.

Leukocytes were obtained in two ways: First, by injecting aleuronat into the pleural or abdominal cavity of animals: $8 \%$ aleuronat is sterilized by boiling for 30 minutes, suspended in $0.9 \%$ salt solution and cooled to the body temperature. The amount to be injected depends on the size of the animal; in rabbits $8.0-10.0 \mathrm{cc}$ of aleuronat suspension may be injected into the pleural cavity, and 20.0-30.0 c c into the abdominal cavity. After from $8-15$ hours the animal is bled to death in order to prevent the inflow of blood into the exudate; then the pleural or abdominal cavity is opened and the exudate withdrawn by means of a pipet. In order to prevent coagulation an equal amount of $1.5 \%$ sodium citrate is added.

The second method is generally applicable, but especially when aleuronat injection cannot be made: Into a $1.5 \%$ solution of sodium citrate in $0.9 \%$ salt solution, from one-half to one-third the volume of blood is introduced, and after shaking well to prevent coagulation, the mixture is centrifugated. The fluid above the corpuscles is removed and replaced. with an equal volume of $0.9 \%$ salt solution, when centrifugation is repeated. This process is again repeated twice or three times in order to free the cells from serum and citrate. After the final centrifugation the thin, white film, which contains comparatively numerous leukocytes, on top of the red corpuscles is removed carefully, mixed with $0.9 \%$ salt solution and used in the experiments.

Tests for Leukocidin.-The Microscopic Method: A mixture of the fluid to be tested for leukocidin and leukocytic suspension is examined microscopically on a warm stage. When leukocytes are placed in suitable streptococcus culture fluid and examined from time to time on the warm stage they are seen to lose their ameboid movement and to change their appearance; small transparent vesicles may appear in the cells; the nucleus becomes irregular, and grantles may gather in the leukocyte which finally may be dissolved.

2. The Bioscopic Method: Ehrlich observed that living cells require a certain amount of oxygen which they appropriate from their surroundings. This ability of the living cell to cause a reduction is the basis of the bioscopic method. The addition of an easily reducible dye to a suspension that contains leukocytes offers a means to determine 
whether the leukocytes are living or dead. I have used methylene blue, prepared according to the following formula; methylene blue, $1.0 \mathrm{cc}$; absolute alcohol, $20.0 \mathrm{cc}$; distilled water, $29.0 \mathrm{cc}$.

The first step in a given case is to determine the minimum quantity of leukocytic suspension which causes a reduction of methylene blue. Different densities of leukocytic suspension are made with $0.9 \%$ salt solution and the mixture made up to $2.0 \mathrm{cc}$. Two drops of methylene blue solution are added. The mixture is covered with a layer of liquid paraffin in order to prevent reoxidation by the air. The tubes are placed in an incubator at $37 \mathrm{C}$. for two hours. Small test tubes about $0.7 \mathrm{~cm}$. or so in diameter are used. If reduction occurs the solution becomes colorless, if no reduction occurs the color remains green.

The second step is to determine the effect of the supposed leukocidin. To twice the minimum quantity of leukocytic suspension causing reduction as determined, different quantities of leukocidin fluid are added and each suspension diluted to $2.0 \mathrm{c} \mathrm{c}$ with $0.9 \%$ salt solution. These mixtures are incubated for $1 \frac{1}{2}$ hours at 37 degrees; at the end of this period two drops of methylene blue solution are added and covered with a layer of liquid paraffin; again they are incubated for 2 hours when the readings are made. If the tubes retain a green color it indicates that something has killed the leukocytes and prevented reduction. If the mixtures are colorless, that is, if reduction has taken place, there has been no lethal effect on the leukocytes. In the tables the results are given as positive $(+$ or \pm ) when the reduction of methylene blue by the leukocytic exudate was prevented by the culture filtrate; that is, when leukocidal effect was demonstrated; otherwise as negative $(0)$.

\section{LEUKOCIDIN PRODUCTION BY VARIOUS STRAINS OF STREPTOCOCCI}

By means of the methylene blue reduction test I have examined a number of different strains of streptococci for the production of leukocidin in serum broth cultures. As a general rule, streptococci, hemolytic as well as nonhemolytic when nonvirulent and easily phagocytable under the influence of normal serum. do not produce any leukocidin demonstrable by the reduction test. Virulent strains, however, produce leukocidin in demonstrable quantities; such strains are not as a rule phagocytable under the influence of normal serum. Most of my experiments have been made with a typical hemolytic streptococcus (Str. pyogenes) originally isolated from a human abscess and subjected 
to several passages through rabbits as well as mice, being of a rather high degree of virulence for these animals. Of the original cultures of green-producing streptococci examined for leukocidin production, a strain from the lung in a case of influenzal bronchopneumonia produced considerable leukocidin. The other strains examined gave negative results except for traces in the case of a coccus isolated from the blood in measles and of another coccus obtained from the brain after death from influenza. I may say also that my results indicate that certain typical pneumococci may produce leukocidal substances, but I have not made a careful study of such production by pneumococci.

The fact that animal passage raises the power of hemolytic streptococci to produce leukocidin is illustrated in table 1 .

TABLE 1

Virulence of Streptococci and Leukocidin Production

\begin{tabular}{|c|c|c|c|}
\hline \multirow{2}{*}{ Culture Filtrate } & \multirow{2}{*}{ Fxudate } & \multicolumn{2}{|c|}{ Results } \\
\hline & & $\begin{array}{l}\text { Original } \\
\text { Culture }\end{array}$ & $\begin{array}{l}\text { Culture after Three } \\
\text { Rabbit Passages }\end{array}$ \\
\hline $\begin{array}{c}1.0 \\
0.75 \\
0.5 \\
0.25 \\
0.125 \\
0.05 \\
0.025 \\
- \\
0.5 \text { (heated to } 60 \mathrm{C} . \\
\text { for } 30 \text { minutes) }\end{array}$ & $\begin{array}{l}0.6 \\
0.6 \\
0.6 \\
0.6 \\
0.6 \\
0.6 \\
0.6 \\
0.6 \\
0.6\end{array}$ & $\begin{array}{l}+ \\
+ \\
0 \\
0 \\
0 \\
0 \\
0 \\
0 \\
0\end{array}$ & $\begin{array}{l}+ \\
+ \\
+ \\
+ \\
+ \\
+ \\
0 \\
0 \\
0\end{array}$ \\
\hline
\end{tabular}

$t=$ leukocidin present. $0=-$ no leukocidin present.

\section{ACID FORMATION AND LEUKOCIDIN PRODUCTION}

It is known that streptococci form acid in cultures. At the time when the existence of streptolysin itself was in doubt, it was suggested that hemolysis by the culture fluid of streptococci was due to the acid in the fluid, but the work of Hellens, ${ }^{12}$ Sekiguchi, ${ }^{13}$ and others, have clearly shown that there is no relation whatever between acid formation and streptolysin. Furthermore, my experiments indicate that acid formation and leukocidin production do not go hand in hand. According to observations made at various intervals, the amount of acid formed is either stationary or increases in the culture fluid (serum and plain or $0.2 \%$ glucose broth, 1:9), after from 48-72 hours, when the amount of leukocidin is found to decrease (table 3 ). Therefore, it seems clear that there is no close relation between the production

12 Ceitralbl. f. Bakt., I, O., 1913, 68, p. 692.

13 Jour. Infect. Dis., 1917, 21, p. 475. 
of leukocidin and acid formation. But it appears that there may be a more definite relationship between the production of a leukocidin and streptolysin, for when streptolysin is at its maximum, leukocidin is also at its maximum.

\section{LEUKOCIDIN PRODUCTION IN BROTH WITH BLOOD SERUM OF VARIOUS ANIMALS}

It seems that the substances produced by streptococci in artificial medium depends on the character of the medium. Thus Besredka ${ }^{14}$ and Ruediger ${ }^{15}$ demonstrated that the streptolysin produced in medium containing blood serum of different animals exhibits characteristic actions on the corpuscles of those animals. The experiments of Hellens indicate that there is produced different amounts of streptolysin according to the serum added to the broth. In order to ascertain whether there is any relationship between leukocidin production and different kinds of serum, I made experiments, the results of which are given in table 2 , and as there shown the largest amount of production occurred in broth with goat or horse setum, than in that with rabbit serum, while that with guinea-pig serum gave the lowest amount.

TABLE 2

Leukocidin Production in Various Kinds of Serum 1 Part Aded to Plain Broth 9 parts

\begin{tabular}{|c|c|c|c|c|c|}
\hline \multirow{2}{*}{ Culture Filtrate } & \multirow{2}{*}{ Exudate } & \multicolumn{4}{|c|}{ Results } \\
\hline & & Goat & Guinea-Pig & Horse & Rabbit \\
\hline $\begin{array}{c}1.0 \\
0.75 \\
0.5 \\
0.25 \\
0.125 \\
0.05 \\
- \\
0.5 \text { heated to } 60 \mathrm{C} \text {. } \\
\text { for } 30 \text { minutes }\end{array}$ & $\begin{array}{l}0.5 \\
0.5 \\
0.5 \\
0.5 \\
0.5 \\
0.5 \\
0.5 \\
\\
0.5\end{array}$ & $\begin{array}{l}+ \\
+ \\
+ \\
+ \\
+ \\
0 \\
0 \\
0\end{array}$ & $\begin{array}{l}+ \\
+ \\
0 \\
0 \\
0 \\
0 \\
0 \\
0\end{array}$ & $\begin{array}{l}+ \\
+ \\
+ \\
+ \\
+ \\
+0 \\
0 \\
0\end{array}$ & $\begin{array}{l}+ \\
+ \\
+ \\
0 \\
+ \\
0 \\
0 \\
0\end{array}$ \\
\hline
\end{tabular}

LEUKOCIDIN PRODUCTION AND TIME

According to Bail, the greatest amount of leukocidin is produced by staphylococci after a growth of 11 days, and Neisser and Wechsberg noted that production began in 4 days and it reached the maximum point after one week.

Substances produced by streptococci in cultures, such as acid and streptolysin, seem to reach the maximum at a fixed time and hence it

14 Ann, de 1'Inst. Pasteur, 1901, 15, p. 880.

15 Jour. Am. Med. Assn., 1903, 41, p. 962. 
would be reasonable to suppose that if leukocidal substances are formed by streptococci, they also will reach the maximum at a fixed time. The results in table 3 show that the greatest amount of leukocidin in this case was present after from 10-24 hours. This relationship is identical with the production of streptolysin. The amount of leukocidin falls after 48 hours and 72 hours of cultivation. The greatest amount of leukocidin appears in comparatively young cultures of streptococci.

TABLE 3

Leukocidin Production Time and Acid Formation

\begin{tabular}{|c|c|c|c|c|c|c|}
\hline \multirow{2}{*}{ Culture Fluid } & \multirow{2}{*}{ Exudate } & \multicolumn{5}{|c|}{ Age of Culture } \\
\hline & & 5 Hours & 8 Hours & 15 Hours & 24 Hours & 48 Hours \\
\hline $\begin{array}{c}0.75 \\
0.5 \\
0.25 \\
0.1 \\
0.05 \\
0.5 \text { heated to } \\
60 \mathrm{C.} \text { for } 30 \\
\text { minutes } \\
\text { Acidity of cul- } \\
\text { ture fiuids }\end{array}$ & $\begin{array}{l}0.5 \\
0.5 \\
0.5 \\
0.5 \\
0.5\end{array}$ & $\begin{array}{l}+ \\
\pm \\
0 \\
0 \\
0\end{array}$ & $\begin{array}{l}+ \\
+ \\
+ \\
+ \\
0\end{array}$ & $\begin{array}{l}+ \\
+ \\
+ \\
+ \\
0\end{array}$ & $\begin{array}{l}+ \\
+ \\
0 \\
0 \\
0\end{array}$ & $\begin{array}{l}0 \\
0 \\
0 \\
0 \\
0\end{array}$ \\
\hline
\end{tabular}

\section{ACTION OF LEUKOCIDIN AND TIME}

The action of leukocidin on leukocytes requires a little time. When I observed the degree of action in mixtures of leukocidin and leukocytes at different intervals I found that the action is as fully developed after 30 minutes as after the lapse of one hour, when it seems to remain stationary. It is also noteworthy that the rapidity of action depends on the amount of leukocidin that is added to the leukocytes; in the mixture in which a large amount of leukocidin is present the action is almost complete in from 30-60 minutes, while in mixtures containing less letkocidin, the same degree of action is realized only after from $1 \frac{1}{2}-3$ hours (table 4 ).

TABLE 4

Leukocidin Action and Time

\begin{tabular}{|c|c|c|c|c|c|}
\hline \multirow{2}{*}{ Oulture Filtrate } & \multirow{2}{*}{ Exudate } & \multicolumn{4}{|c|}{ Time and Results } \\
\hline & & $1 / 2$ Hour & 1 Hour & 11/2 Hours & 3 Hours \\
\hline $\begin{array}{c}1.0 \\
0.75 \\
0.5 \\
0.25 \\
0.125 \\
0.05 \\
- \\
0.5 \text { heated to } 60 \mathrm{C} . \\
\text { for } 30 \text { minutes }\end{array}$ & $\begin{array}{l}0.5 \\
0.5 \\
0.5 \\
0.5 \\
0.5 \\
0.5 \\
0.5 \\
0.5\end{array}$ & $\begin{array}{l}+ \\
+ \\
\pm \\
0 \\
0 \\
0 \\
0 \\
0\end{array}$ & $\begin{array}{l}+ \\
+ \\
+ \\
+ \\
\pm \\
0 \\
0 \\
0\end{array}$ & $\begin{array}{l}+ \\
+ \\
+ \\
+ \\
+ \\
0 \\
0 \\
0\end{array}$ & $\begin{array}{l}+ \\
+ \\
+ \\
+ \\
\pm \\
0 \\
0 \\
0\end{array}$ \\
\hline
\end{tabular}




\section{LEUKOCIDIN ACTION ON VARIOUS LEUKOCYTES}

Are all leukocytes attacked alike by leukocidin or is there a difference in their susceptibility? In order to answer these questions I examined the action of streptococcus filtrate on human, rabbit, guineapig, rat, mouse and dog leukocytes, and I found very little difference in the result. The streptococcus used was the one obtained from a human abscess and passed through 5 rabbits and 15 mice.

As to the question whether the kinds of leukocytes are equally susceptible, I studied rabbit leukocytes. Polynuclear leukocytes were attacked first, while mononuclear leukocytes, particularly lymphocytes, showed strong resistance. In other words, even in case of contact with a large quantity of leukocidin for several hours, the lymph cells frequently remained unchanged. Thus it may be said that mononuclear leukocytes, particularly the lymph cells, are more resistant than other leukocytes.

According to my results, the susceptibility of the leukocytes in rabbits about one month old, is less than in older animals.

Neisser and Wechsberg found that staphyloleukocidin did not destroy kidney cells. I tested the action of streptoleukocidin on liver, kidney, spleen and marrow cells from rabbits killed by bleeding, the organs being cut into small pieces with a sterilized knife and the pieces put in four times their volume of $0.9 \%$ salt solution and agitated thoroughly. The cells thus freed were used for experiments, but I could not obtain any striking results. When the mixtures of cells and leukocidin were kept at $37 \mathrm{C}$. for from 3-4 hours, a comparatively large quantity of the leukocidin would kill the cells, especially liver cells; that is, $0.5-0.25 \mathrm{cc}$ of leukocidin killed a certain number of cells within from 3-4 hours. Generally, the organ cells were much more resistant that leukocytes.

$$
\text { RESISTANCE OF LEUKOCIDIN TO HEAT, ETC. }
$$

The resistance of leukocidin to heat was examined with the results shown in table 5 . There seems to be no effect after heating at from 45 to $48 \mathrm{C}$. for one hour; heating at $55 \mathrm{C}$. for one-half hour caused a little loss of action; when the leukocidin was left for one-half hour at from 58-60 C. it lost its power to attack leukocytes. 
Investigation of the decrease or loss of leukocidal power under different conditions has shown that when kept in the icebox at 4-5 degrees, the leukocidin in streptococcus filtrates after 4 days suffered no change in power, but a decrease in power to 0.25 from 0.05 was noted after from 7-10 days. At $0 \mathrm{C}$. the leukocidin kept much better and its power showed no sign of change after 2 weeks. At $37 \mathrm{C}$. the power of the leukocidin did not decrease after 3, 7, and 15 hours, but it began to fall after 24 hours. At room temperature (about 26 C.), the leukocidin showed a marked decrease in power in from 2-4 days.

TABLE 5

EFFEct OF Heat ON LeUKocidin

\begin{tabular}{|c|c|c|c|c|}
\hline \multirow{2}{*}{ Culture Filtrate } & \multirow{2}{*}{ Exudate } & \multicolumn{3}{|c|}{ Results } \\
\hline & & $\begin{array}{l}550 \text {. for } \\
15 \text { Minutes }\end{array}$ & $\begin{array}{c}55 \mathrm{C} . \text { for } \\
30 \text { Minutes }\end{array}$ & $\begin{array}{c}58 \mathrm{C} \text {. for } \\
30 \text { Minutes }\end{array}$ \\
\hline $\begin{array}{l}1.0 \\
0.75 \\
0.5 \\
0.25 \\
0.125 \\
0.05 \\
0.025 \\
-\end{array}$ & $\begin{array}{l}0.6 \\
0.6 \\
0.6 \\
0.6 \\
0.6 \\
0.6 \\
0.6 \\
0.6\end{array}$ & $\begin{array}{l}+ \\
+ \\
+ \\
+ \\
+ \\
+ \\
0 \\
0\end{array}$ & $\begin{array}{l}+ \\
+ \\
+ \\
\pm \\
0 \\
0 \\
0 \\
0\end{array}$ & $\begin{array}{l}0 \\
0 \\
0 \\
0 \\
0 \\
0 \\
0 \\
0\end{array}$ \\
\hline
\end{tabular}

Can leukocidin be reactivated? The results of many experiments to revive the activity of leukocidal streptococcus filtrates after being heated to $60 \mathrm{C}$. for 30 minutes, by addition of a small amount of active leukocidin were all negative. It looks as if streptoleukocidin once rendered inactive cannot be reactivated, and consequently in this respect it resembles the toxins.

\section{DOES LEUKOCIDIN COMBINE WITH LEUKOCYTES AT LOW TEMPERATURE?}

To $10 \mathrm{cc}$ of leukocidal culture fluid diluted with an equal volume of $0.9 \%$ salt solution, an excess of leukocytes was added. The leukocytes used were obtained by centrifugating aleuronat exudate and suspending the cells in $0.9 \%$ salt solution. Such mixtures were left at room temperature or in the icebox for 3 hours, then centrifugated and the clear supernatant fluid examined according to the method described. It was found that the leukocidin and the leukocytes united, whether left at room temperature or in the icebox, as fresh leukocytes afterward were not attacked by the supernatant fluid. 


\section{SIMILARITIES AND DIFFERENCES OF STREPTOLEUKOCIDIN} AND STREPTOLYSIN

Streptoleukocidin may be regarded as a toxin which affects leukocytes and streptolysin as a toxin which lakes red corpuscles, and it becomes necessary at this point to describe the similarities and differences of these two substances.

According to the results described previously, ${ }^{11}$ streptolysin is most abundant in cultures about from 10-24 hours old. Only small amounts are found in cultures less than 5 hours or more than 48 hours old. With streptoleukocidin the condition is almost similar, the largest amount being obtained in the fluid of cultures between 10 and 24 hours old. Thus there seems to be no significant difference between leukocidin and streptolysin in point of time of production.

The power to produce streptolysin is retained by streptococci even when avirulent to animals and long cultivated artificially, but when streptococci are passed through animals, that is, become more virulent, the production of streptolysin is increased. Streptococcus leukocidin has a somewhat similar relationship, but $I$ have found that nonvirulent streptococci may produce streptolysin freely but no demonstrable streptoleukocidin whatever. I have obtained lytic action by the culture fluids of several strains of streptococci when there was no trace of leukocidin, and it seems clear that a hemolytic streptococcus that produces no leukocidin nevertheless may give rise to streptolysin.

No hemolysis takes place in a mixture of streptolysin and red corpuscles kept at zero for from 3-5 hours, but the lysin and corpuscles combine, and the supernatant liquid obtained by centrifugating this mixture does not cause hemolysis. Similarly, in leukocidal experiments with the supernatant liquid no destruction of leukocytes occurs. When a mixture of leukocytes and leukocidin is kept at room temperature or in an icebox (4-5 C.) for 3 hours, a union of the two takes place, and the centrifugated fluid causes no leukocytic destruction, but this fluid is definitely hemolytic, its lytic power being much less, however, than that of the nontreated filtrate.

The resistance of streptolysin to heat is greater than that of streptoleukocidin, that is, leukocidin when heated at $55 \mathrm{C}$. for 30 minutes suffers but little effect. After being heated for half an hour at $58 \mathrm{C}$. it loses completely its power to attack leukocytes, while streptolysin when so heated retains its power to cause lysis. 


\section{ANTILEUKOCIDIC ACTION OF NORMAL AND ANTI- STREPTOCOCCUS SERUM}

It has been found that the normal serum of different animals as a rule possesses some power to neutralize specific venomous substances. The action of normal serum on the leukocidin produced by streptococci has been studied, the serum being first heated at $56 \mathrm{C}$. for 30 minutes, to destroy any lytic action on rabbit leukocytes, and then a mixture of such heated normal serum and leukocidin kept at $37 \mathrm{C}$. for one hour when leukocytes were added. Generally speaking, the results indicated that the normal serum of different animals possesses antileukocidal properties and that human and horse serums possess this power in higher degree than certain other serums (see table 6). While heating normal serums for 30 minutes at $60-65 \mathrm{C}$. does not affect its antileukocidal power, heating at $70 \mathrm{C}$. for 30 minutes completely destroys this power. I have obtained results indicating that after recovery from scarlet fever the serum may have increased antileukocidal power.

TABLE 6

Action of Antileukoctoal Rabett Serum

\begin{tabular}{|c|c|c|c|c|c|c|}
\hline \multirow{3}{*}{$\begin{array}{l}\text { Culture } \\
\text { Filtrate }\end{array}$} & \multirow{3}{*}{ Exudate } & \multirow{3}{*}{ Serum } & \multicolumn{4}{|c|}{ Results } \\
\hline & & & \multicolumn{3}{|c|}{ Normal Serum } & \multirow{2}{*}{$\begin{array}{l}\text { Immun } \\
\text { Rabbit } \\
\text { Serum }\end{array}$} \\
\hline & & & Human & Horse & Rabbit & \\
\hline $\begin{array}{l}0.25 \\
0.25 \\
0.25 \\
0.25 \\
0.25 \\
0.25 \\
0.25 \\
0.25\end{array}$ & $\begin{array}{l}0.6 \\
0.6 \\
0.6 \\
0.6 \\
0.6 \\
0.6 \\
0.6 \\
0.6\end{array}$ & $\begin{array}{l}1.0 \\
0.75 \\
0.5 \\
0.25 \\
0.125 \\
0.05 \\
0.025 \\
-\end{array}$ & $\begin{array}{l}0 \\
0 \\
0 \\
0 \\
+ \\
+ \\
+ \\
+\end{array}$ & $\begin{array}{l}0 \\
0 \\
0 \\
0 \\
0 \\
+ \\
+ \\
+\end{array}$ & $\begin{array}{l}0 \\
0 \\
0 \\
+ \\
+ \\
+ \\
+ \\
+\end{array}$ & $\begin{array}{l}0 \\
0 \\
0 \\
0 \\
0 \\
0 \\
+ \\
+\end{array}$ \\
\hline
\end{tabular}

With a view to finding a solution to the question whether the antileukocidin in normal serum is derived from leukocytes by secretion, the effect of fluids in which leukocytes has been kept was tested, but the result was negative.

First, $50-100 \mathrm{cc}$ of an equal volume of plain broth and $0.9 \%$ salt solution were injected intraperitoneally in a rabbit, and after from $6-8$ hours the animal was bled to death and the exudate immediately removed from the peritoneal cavity. The exudate was mixed at once with salt solution, containing $1 \%$ sodium citrate and centrifugated, and the leukocytes separated and suspended in salt solution. The proper density of the suspension was found to be a mixture which in a $2 \mathrm{~cm}$. test tube barely permitted letters to be seen through the fluid. 
This suspension was left at $37 \mathrm{C}$. for 3 hours, and then again centrifugated. The upper clear liquid was tested for antileukocidal action.

To test whether leukocytic extracts are antileukocidal, leukocytes were obtained as described, and suspensions of the same concentration rapidly heated at $50 \mathrm{C}$. for 30 minutes, thus killing all the leukocytes contained therein. Then the suspension was left at $37 \mathrm{C}$. for 2 hours, centrifuged and the supernatant liquid tested for antileukocidal action; the results indicated clearly that the leukocytic extract had some antileukocidal action. Heated at $60-65 \mathrm{C}$. for 30 minutes such extracts were still antileukocidic, but when heated at $70 \mathrm{C}$. for 30 minutes this power was reduced markedly.

The question whether antistreptococcus serum has antileukocidal action is a significant one from the standpoint both of theory and practice. I have examined the action of antistreptococcus serum as follows :

A.-The strain of Str. pyogenes, isolated about one year ago from a human abscess, was used to immunize a rabbit. The first two injections were made with the bacteria heated at $60 \mathrm{C}$. from 24-hour cultures in $0.2 \%$ glucose serum broth and the last three with living bacteria. All injections were made intravenously. The blood was obtained for examination from 7-14 days after the last injection. The serum used agglutinated the streptococcus at $1: 2,560$ and had an opsonic index of 1.46 .

B.- The streptococcus strain now used was a strongly virulent one, having been passed through 5 rabbits and 15 mice. The method of immunization was the same as just outlined. The serum in this case agglutinated at 1:1,280; while the coccus was nonphagocytable in normal rabbit serum, the immune serum caused marked phagocytosis. The results of the tests for antileukocidin were not decisive. Although rabbit $B$ serum gave a stronger antileukocidal action than rabbit $A$ serum and normal rabbit serum, the action was not so pronounced but that it may have been due to normal antileukocidin. And later, serum from a rabbit immunized with a streptococcus which had been passed through 5 rabbits and 24 mice was found to have no more antileukocidal action than normal rabbit serum. This immune serum agglutinated in 1:1,280; the streptococcus was nonphagocytable with normal rabbit serum, but with the immune serum an average of 8 cocci per letkocyte were taken up. 


\section{ANTISTREPTOLEUKOCIDAL SERUM}

When a bacterial toxin is injected into the animal body, antitoxin may be produced. As streptococcus leukocidin seems to be a toxin produced by streptococci, the question arises whether a specific antileukocidin can be obtained. As the experiments just detailed indicate that we cannot demonstrate any antileukocidal action on the part of antistreptococcus serum, we might infer that immunization with leukocidin will not yield striking results.

Fullgrown and healthy rabbits were chosen for immunization. The material for injection was freshly made each time, and 8 injections were given at intervals of from 4-7 days. The amount for the first injection was $0.5 \mathrm{c} \mathrm{c}$, and this amount was gradually increased to $2.0 \mathrm{cc}$. The first injection was given subcutaneously, the next intravenously, and alternatingly thereafter. The serum was obtained from 7-14 days after the last injection. The streptococcus strain used in this experiment had been passed through 5 rabbits and 27 mice and cultivated for 15 hours in a medium of plain broth and inactive goat serum 2-1.

According to the results of the tests (table 6), there seemed to be a distinct increase of anti-action of the immune as compared with normal serum, $0.05 \mathrm{c} \mathrm{c}$ of the immune serum having the same effect as $0.5 \mathrm{cc}$ of normal serum. I have examined the antileukocidal action of normal rabbit serum many times, but $I$ have not yet found such marked action as that of the serum of the rabbit immunized with leukocidin, and I am led to regard this action as due to the presence of an antibody. The antiserum had also a stronger netutralizing action on heterologous streptoletukocidin than normal serum.

Does antileukocidal serum promote phagocytosis? Virulent streptococci not only remain unmolested by leukocytes in phagocytic mixtures, but often the leukocytes are broken up and lost, due to the leukocidin produced by the cocci. Hence, when an antileukocidal serum that neutralizes leukocidin is added, the functional disturbances and destruction of leukocytes ought to be prevented. I have studied phagocytosis by guinea-pig leukocytes in mixtures of virulent streptococci (passed through 5 rabbits and 24 mice) and antileukocidal serum, and the average number of bacteria taken up by each leukocyte was 8 , the largest individual number being 24 . This streptococcus was absolutely nonphagocytable in normal serum. A heterologous streptococcus, nonphagocytable in normal serum, was rendered freely phagocytable by antileukocidal serum, the average number taken up per leukocyte 
being 14. According to these results, antileukocidal serum not only accelerates the phagocytosis of the homologous streptococcus strain, but also facilitates the phagocytosis of heterologous strains.

In an experiment to test the protective power of this antileukocidal serum against streptococci, I used a 24-hour serum broth culture of which $0.001 \mathrm{c} \mathrm{c}$ killed mice. Of this culture $0.002 \mathrm{cc}$ were injected intraperitoneally 15 hours after varying quantities of immune serum, heated at $56 \mathrm{C}$. for 30 minutes, had been injected subcutaneously. According to the results the immune serum had definite protective power.

\section{COMPARISON OF STREPTOLEUKOCIDIN AND STAPHYLOLEUKOCIDIN}

According to Neisser and Wechsberg's ${ }^{10}$ results, the leukocidin produced by certain pyogenic staphylococci seems to be similar to the leukocidin produced by streptococci-the resistance to heat, the action on leukocytes, and the relation of production to virulence seem about the same. In my experiments Staph. aureus was used, and I found that $0.1 \mathrm{cc}$ of the filtrate (Maasen filter) of a plain broth culture 4 days old killed leukocytes (filtrate $0.06 \mathrm{cc}$, exudate $0.5 \mathrm{cc}$, and salt solution $1.4 \mathrm{cc}$ ), but this effect was not suspended by the serum of a rabbit injected with streptoleukocidin, which, however, was neutralized by the serum (table 7 ).

TABLE 7

Action of the Antistreptoleukocidal Serum Against Staphylococcus Leukocidin

\begin{tabular}{|c|c|c|c|c|c|}
\hline \multirow{2}{*}{$\begin{array}{c}\text { Serum } \\
\text { (Normal or } \\
\text { Immune) }\end{array}$} & \multirow[b]{2}{*}{ Exudate } & \multicolumn{2}{|c|}{ Antistreptolenkocidal Serum } & \multicolumn{2}{|c|}{ Normal Serum } \\
\hline & & $\begin{array}{l}\text { Strepto- } \\
\text { leukocidin } \\
0.2 \mathrm{ce}\end{array}$ & $\begin{array}{l}\text { St aphylo- } \\
\text { leukocidin } \\
\text { o.1 c c }\end{array}$ & $\begin{array}{l}\text { Strepto- } \\
\text { leukocidin } \\
0.2 \mathrm{cc}\end{array}$ & $\begin{array}{l}\text { Staphylo- } \\
\text { leukocidin } \\
0.1 \mathrm{c} \text { c }\end{array}$ \\
\hline $\begin{array}{l}1.0 \\
0.75 \\
0.5 \\
0.25 \\
0.1 \\
0.05 \\
0.025 \\
- \\
-\end{array}$ & $\begin{array}{l}0.5 \\
0.5 \\
0.5 \\
0.5 \\
0.5 \\
0.5 \\
0.5 \\
0.5 \\
0.5\end{array}$ & $\begin{array}{l}0 \\
0 \\
0 \\
0 \\
0 \\
0 \\
+ \\
+ \\
0\end{array}$ & $\begin{array}{l}0 \\
0 \\
0 \\
0 \\
+ \\
+ \\
+ \\
+ \\
0\end{array}$ & $\begin{array}{l}0 \\
0 \\
0 \\
0 \\
+ \\
+ \\
+ \\
+ \\
+\end{array}$ & $\begin{array}{l}0 \\
0 \\
0 \\
0 \\
+ \\
+ \\
+ \\
+ \\
0\end{array}$ \\
\hline
\end{tabular}

\section{SUMMARY}

Streptococci, like certain other bacteria, produce a toxic substance - apparently a toxin - that destroys leukocytes. In serum-broth medium the largest amount of streptoleukocidin is produced in from 10-24 hour; after that the production falls. The largest amount of 
leukocidin was obtained in broth with goat serum and horse serum, the next largest amount with rabbit serum, while guinea-pig serum gave the least. There is a definite relation between the volume of production and virulence-virulent streptococci produce more leukocidin by far than avirulent, which may produce none at all.

Streptoleukocidin is rendered inactive when heated to from 58 to $60 \mathrm{C}$. for 30 minutes, and it is an unstable substance. Once rendered inactive it cannot be made active again by the addition of small quantities of fresh leukocidal culture fluid. The leukocidin and leukocytes unite at room temperature as well as in the icebox.

Normal serum and leukocytic extract possess antileukocidal action; this anti-action is lost when the fluids are heated at $70 \mathrm{C}$. for 30 minutes.

It seems difficult to produce antileukocidal effects by immunizing rabbits with streptococci, but easier by injecting leukocidal culture fluids. Antileukocidal immune serum not only exercises antiletkocidal action against homologous and heterologous streptoleukocidin, but also possesses strong opsonic powers, rendering virulent streptococci, homologous as well as heterologous, easily phagocytable.

Streptoleukocidin appears to be distinct from streptolysin and antistreptoleukocidin does not neutralize staphyloleukocidin. 